\title{
WORLD-CLASS UNIVERSITIES COMO CONCEITO EM DISPUTA NA EDUCAÇÃO SUPERIOR
}

\author{
JoSÉ VIEIRA DE SOUSA \\ Universidade de Brasília (UnB), Brasilia, Distrito Federal, Brasil
}

\begin{abstract}
Resumo: O artigo tem como objetivo analisar o conceito de world-class universities como objeto de disputa no competitivo campo da educação superior, partindo da premissa de que, no mundo globalizado, sua origem e consolidação ocorrem tomando como referência básica padrões internacionais de qualidade. De natureza teórica, o trabalho problematiza a educação superior na economia do conhecimento, de maneira articulada à exploração de dados produzidos pelos dois principais rankings que classificam essas universidades - Academic Ranking of World Universities e Times Higher Education World University Rankings - publicados, respectivamente, nos anos de 2019 e 2020 . Conclui-se que o conceito desse novo modelo de universidade considera critérios e indicadores globais de qualidade, mas também a ação das demais universidades que fazem parte do campo da educação superior.
\end{abstract}

Palavras-chave: Educação superior. Economia do conhecimento. World-class universities.

\section{CONSIDERAÇÕES INICIAIS}

O objetivo deste artigo é refletir sobre o conceito de world-class universities como objeto de disputa no competitivo campo da educação superior, considerando que, na sociedade globalizada, a consolidação desse novo modelo de universidade vem acontecendo a partir da definição de critérios e padrões internacionais de qualidade.

O artigo situa o tema no contexto mais amplo da relação educação superior e economia do conhecimento, partindo da premissa de que os princípios desse tipo de economia têm influenciado substantivamente a construção do conceito de world-class universitie. Para tanto, focaliza, por um lado, aspectos teórico-conceituais relativos a esse conceito, situando-os no cenário mais amplo da educação superior e, por outro, algumas evidências empíricas dos dois principais rankings que classificam essas universidades Academic Ranking of World Universities (ARWU) e Times Higher Education World University Rankings (THE) - publicados, respectivamente, nos anos de 2019 e 2020.

A discussão feita no texto considera o cenário mais amplo das grandes e velozes transformações ocorridas no campo da educação superior mundial nas últimas décadas. Nesse contexto, têm ganhado centralidade as discussões sobre um novo modelo de universidade - world-class universitie -, enfatizando que sua instalação ocorre no competitivo campo da educação superior, no qual busca se instalar e permanecer. Em consequência, sua abordagem requer que seja considerada a complexidade dos 
contextos sociais nos quais ela se insere nas diferentes regiões do planeta. $O$ padrão de excelência perseguido por esse tipo de universidade subjaz a uma cultura de luta e competição, cuja finalidade é assegurar sua distinção diante das demais no campo do qual fazem parte.

Estruturalmente, o texto está organizado em quatro partes, além das considerações iniciais e finais. A primeira parte aborda a noção de campo formulada por Pierre Bourdieu como importante constructo teórico-metodológico para a discussão do sistema de educação superior, partindo da premissa de que este configura-se, sobretudo, em espaço competitivo e de disputa por diferentes atores interessados em sua dinâmica. A segunda analisa tendências atuais evidenciadas por estudos sobre educação superior, enfatizando elementos que concorrem para a compreensão de sua reestruturação nas últimas décadas. A terceira situa a educação superior na economia do conhecimento, destacando desafios e dilemas relativos à reestruturação do papel da universidade no contexto do mundo globalizado e da sociedade do conhecimento. A quarta, última parte, problematiza o conceito de world-class universitie como um objeto em disputa no campo da educação superior, destacando as características e os atributos delas exigidos para ocupar posição de destaque nos rankings internacionais à luz de critérios e padrões globais de qualidade.

Em seu conjunto, as ideias debatidas no texto convergem para a premissa de que as world-class universities buscam se instalar e distinguir-se das demais em novos contextos marcados por grandes transições sociais, econômicas e políticas. Dotados de grande complexidade, esses contextos mostram que o novo modelo de universidade se instala em um campo de jogo de poder e de interesses de atores diversos - o da educação superior - cuja dinâmica vem sendo influenciada pelos princípios da economia do conhecimento.

\section{A NOÇÃO DE CAMPO COMO CONSTRUCTO PARA O ESTUDO DA EDUCAÇÃO SUPERIOR}

A noção de campo como estruturador das relações sociais formulada por Pierre Bourdieu (1930-2002) constitui um importante constructo teórico-metodológico para a compreensão do cenário da educação superior na sociedade globalizada e, de forma mais específica, da luta nele travada pelas world-class universities. No campo de disputa, do qual faz parte cada uma delas, procura construir sua identidade tomando as outras como referência, a partir de relações estabelecidas entre elas. É a universidade que aponta as bases para a dinâmica desse campo, de forma que "mesmo as instituições não-universitárias situam-se, em certa medida, em relação a ela, em situação de complementaridade ou de concorrência mais ou menos notória" (CHARLE; VERGER, 1996, p. 7-8).

$\mathrm{Na}$ visão de Bourdieu (2010), quanto mais complexa for a sociedade, mais conta com campos diversos - político, científico, cultural, educacional, artístico, etc -, os quais, possuindo sua própria dinâmica e especificidades, apontam as condicionalidades para estruturar a ação dos agentes. "Compreender a gênese social de um campo, é aprender aquilo que faz a necessidade específica da crença que o sustenta, do jogo de linguagem que nele se joga, das coisas materiais e simbólicas em jogo que nele se geram" (p. 69). 
SOUSA, J. V. de

Com base nesse autor, o campo pode ser definido como um espaço social dotado de estrutura própria - relativamente autônoma sobre outros campos sociais - e de objetivos específicos, que the garantem uma lógica particular de estruturação e funcionamento. "Para que um campo funcione, é preciso que haja objetos de disputas e pessoas prontas para disputar o jogo [...]" (BOURDIEU, 1983, p. 90). Isso faz com que os atores pensem e utilizem estratégias com a finalidade de participar da luta que no campo se instala, em torno dos objetos que lhes são próprios e constituem a razão da disputa realizada nesse mesmo campo.

As relações objetivas que configuram o campo podem ser de aliança e/ou conflito, de concorrência e/ou de cooperação entre posições diferenciadas, socialmente definidas e independentes das características dos agentes que os ocupam. É nesse contexto interpretativo que se torna possível pensar a educação superior, a partir de sua inserção no campo educacional mais amplo e, em termos mais específicos, a luta da qual as world-class universities participam, nesse espaço social, visando a ocupar posições que Ihes assegurem certa visibilidade nos rankings internacionais.

\section{CENÁRIOS E TENDÊNCIAS DA EDUCAÇÃO SUPERIOR MUNDIAL}

Como tema interdisciplinar, se a educação superior possibilita a criação de núcleos de discussão a seu respeito, em distintas regiões do mundo, por outro, tem lidado com a dificuldade de propor uma metodologia suficientemente adequada à sua investigação, face às suas grandes transformações na sociedade contemporânea. Todavia, ainda que enfrente esse dilema, tem se configurado, cada vez mais, em um espaço social de expressiva importância para a compreensão do projeto vislumbrado por essa mesma sociedade, bem como estimulado estudos a seu respeito. Em consequência, muitos pesquisadores vêm se organizando em vários grupos nacionais e internacionais, como, por exemplo, a Association for Institucional Research in The United States, considerada, atualmente, uma das maiores organizações voltadas para pesquisa no mundo. $\mathrm{Na}$ Europa, nos últimos trinta anos, a European Association for Institucional Research tem buscado expandir seus estudos para aspectos mais abrangentes da educação superior, ultrapassando o tradicional foco da pesquisa institucional (ALTBACH; SALMI, 2011).

Nas últimas décadas, um expressivo número de estudos empíricos tem sido produzido sobre os sistemas de educação superior, explorando aspectos diversos de sua dinâmica na sociedade globalizada. Um desses temas - taxa de escolarização bruta - foi investigado pela Organização das Nações Unidas para a Educação, a Ciência e a Cultura (Unesco), no período entre 2004 e 2016. Considerando dois indicadores básicos - taxa de transição do ensino secundário para a educação superior (número de alunos que estavam matriculados no último ano do ensino secundário) e taxa bruta de escolarização (quantidade de estudantes matriculados no primeiro ano da educação superior) - o estudo constatou que houve aumento de $19 \%$ para $34 \%$, no referido período (UNESCO, 2017).

Paralelamente, um considerável número de pesquisadores tem se dedicado a discutir a expansão quantitativa dos sistemas de educação superior, de maneira articulada ao reconhecimento do crescente aumento de sua importância no mundo contemporâneo (ENDERS, 2002; GARCÍA GUADILLA, 2004; ALTBACH, 2006; TROW, 2011). Alguns outros temas, como expansão, avaliação, financiamento e democratização, não 
são novos, porém permanecem sendo discutidos em articulação com outros mais recentes. Nesse último caso, merecem destaque: (i) arquiteturas acadêmicas (FRANCO; MOROSINI, 2017); (ii) repercussões do modelo gerencial na própria organização administrativa acadêmica da universidade (MOHRMAN; BAKER, 2008); (iii) critérios adotados visando o padrão de excelência definido na construção do conceito de worldclass universities (ALTBACH, 2004); internacionalização (KNIGHT, 2012; DE WIT, 2013; MOROSINI, 2014; (iv) globalização, inovações tecnológicas e produção de conhecimento (LEMERT; ELLIOT; 2010); (v) constituição de sistemas de elite, sistemas de massa e sistemas de acesso universal na educação superior (TROW, 2011).

No que tange ao papel e uso da universidade, ganharam grande visibilidade os estudos de Kerr (2005) e Scott (2006). Nesse contexto, as pesquisas revelam que da universidade tem sido exigida grande plasticidade e um discurso que se mostre capaz de induzi-la a uma performance de sucesso. Dela, é esperado que revele estar em "um estado constante de orientação para a mudança. Tal organização está fundada nas capacidades de auto-adaptação e de adaptação a uma sociedade em mudança" (CLARK, 2002, p. 23).

Em relação a um amplo diagnóstico da realidade da educação superior em diversas regiões do mundo, merece destaque a pesquisa coordenada por Altback; Salmi (2011). O estudo contou com a colaboração de um grande número de pesquisadores do tema vinculados a universidades e centros de investigação com forte interesse em compreender como se configura a educação superior nos cinco continentes. Dele, resultou um conjunto de doze trabalhos que aprofundam o debate sobre o tema nas seguintes regiões do planeta: África Subsaariana; América Latina e Caribe; Austrália e Nova Zelândia; Canadá; China; Estados Unidos; Europa Central e Oriental; Europa Ocidental; Federação Russa; Japão; Região Árabe e Sul da Ásia. De maneira geral, esse estudo confirmou que os sistemas de educação superior dos países e regiões do mundo mostram peculiaridades e diferenças significativas explicadas pelas suas próprias condições de construção. Em outros casos, suas características estão diretamente associadas à história dos seus respectivos países ao serem colonizados por outros países mais desenvolvidos.

Nas várias regiões do mundo, órgãos públicos, entidades privadas, organismos internacionais, associações de dirigentes de instituições públicas e privadas, agências de fomento à pesquisa, centros de estudos, sindicatos patronais e de trabalhadores, dentre outros, produzem olhares variados sobre os sistemas de educação superior. Em maior ou menor grau, esses olhares traduzem interesses em relação a um campo que comporta interpretações múltiplas tanto dos pesquisadores ligados à academia como do próprio Estado a respeito dos seus subcampos público e privado. Quanto às reformas em curso, verifica-se que, mesmo definidas na dimensão global/regional, suas repercussões fazemse notar, também, nas universidades, em nível local (OLIVEIRA; MORAES, 2016).

O campo da educação superior comporta uma pluralidade de atores que podem ser vinculados a três grandes grupos. O primeiro diz respeito aos atores sociais do próprio campo, cuja atuação visa fortalecê-lo; o segundo conta com atores que representam a esfera burocrática do Estado; e o terceiro é formado por atores de outros campos sociais interessados naquilo que é disputado no da educação superior - ciência, inovação, patentes, formação acadêmica, título, prestígio profissional e institucional etc. Esses diferentes grupos de atores e, consequentemente, as instituições às quais estão 
vinculados, desenvolvem suas ações em um campo de disputas que podem variar de intensidade, duração e alcance, dependendo do contexto globalizado no qual se manifestam.

A diversidade e heterogeneidade institucional do campo em questão implica examiná-lo à luz de uma lógica que focalize não somente centros de ensino e produção original de conhecimentos, mas também outras instituições que, juntas com aqueles, traduzem sua totalidade. Essa postura reflexiva é importante porque pode contribuir para ampliar o conhecimento sobre as grandes mudanças ocorridas na educação superior mundial, considerando tanto as políticas públicas formuladas para o setor quanto as respostas que ele tem apresentado para as demandas sociais. Além disso, ajuda a entender que ela tem se constituído em um campo acadêmico de extrema complexidade e de fundamental importância para os projetos políticos dos países. Diante disso, é razoável supor "que o tipo de futuro que teremos em boa parte vai depender das respostas que hoje dermos aos dilemas da educação superior. Por tudo isso, é importante refletir sobre as funções que exerce na construção da sociedade" (DIAS SOBRINHO, 2010, p. 44).

No mundo globalizado, o perfil acadêmico das instituições de educação superior varia em função de uma multiplicidade de critérios, como as áreas do conhecimento, os seus diversos cursos, os programas desenvolvidos, as marcas distintivas que constroem no campo formado por elas, além da imagem que desejam apresentar ao público que as buscam, visto que este também possui perfis variados. Na atualidade, critérios como esses justificam a existência de sistemas nacionais de educação superior nos vários continentes que contam com milhares de instituições e milhões de estudantes (ALTACH, 2006).

\section{EDUCAÇÃO SUPERIOR E ECONOMIA DO CONHECIMENTO NA SOCIEDADE GLOBALIZADA}

No mundo globalizado, o próprio campo da educação superior produz e sofre os efeitos de determinadas tensões, as quais acabam provocando a necessidade de segmentá-lo. Nesse cenário, a previsão é de que "a capacidade do ensino [da educação] superior global cresça mais que 150\% no primeiro triênio do século XXI" (HUDZIK, 2013, p. 52). Defendendo a existência de globalizações - e não de globalização -, Santos (2002) sustenta que tal fenômeno acaba provocando relações de dominação econômica entre blocos de países, o que tem repercutido fortemente na educação superior.

As grandes transformações atualmente verificadas no campo da educação superior ocorrem em contextos emergentes, que se mostram associados à complexidade daquelas. Conceitualmente, esses contextos podem ser entendidos como "configurações em construção na educação superior observadas em sociedades contemporâneas e que convivem em tensão com concepções pré-existentes, refletoras de tendências históricas" (MOROSINI, 2014, p. 386). Na visão da autora, uma característica marcante deles é a existência de um sistema de educação superior complexo, heterogêneo, e que se revela, do ponto de vista social, segmentado, visto que conta, ao mesmo tempo, com macro universidades e multicampos que apresentam estruturas bastante diferenciadas.

Nessa perspectiva, os contextos emergentes correspondem a espaços de transição nas propostas de educação superior, sendo passíveis de assumir níveis variados de complexidade, dependendo de suas características nos vários países, embora algumas delas possam se mostrar relativamente comuns. Essa possibilidade existe considerando, 
sobretudo, "a dialética da continuidade e da mudança" (FRANCO, ZITKOSKI; FRANCO, 2016, p. 17) implícita à configuração da educação superior nos referidos contextos.

É nesses contextos e em um mundo marcado pela globalização que emerge a economia do conhecimento, que pode ser definida "como a mobilização das competências empresariais, acadêmicas e tecnológicas com o objetivo de melhorar o nível de vida das populações" (SQUIRRA, 2005, p. 262). Na ampliação da compreensão de sua dimensão conceitual, esse tipo de economia "(Knowledge-based economy) também pode ser interpretada como uma justificação ideológica do desenvolvimento baseado na produção e na apropriação de bens comuns intangíveis" (AZEVEDO, 2012, p. 3).

Tendo passado a ganhar força no final da década de 1990, esse tipo de economia é construído a partir de critérios básicos, como renda per capita/desenvolvimento humano e capacidade de gerar conhecimentos, transformando-os em riquezas. Nesse contexto, "o capital produtivo já não se contenta com a exploração da força de trabalho na obtenção de mais valia [pois] o conhecimento tem papel cada vez mais central e estratégico na chamada "economia do conhecimento" (OLIVEIRA, 2015, p. 347-grifos no original).

$\mathrm{Na}$ economia do conhecimento, as universidades têm passado a assumir a condição de atores-chave do processo de desenvolvimento dos países. Nesse cenário, tendem a atender uma agenda supranacional articulada ao controle de resultados por meio do estabelecimento de classificações internacionais, que resultam em seu posicionamento em determinado ranking. Desse ponto de vista, vão se transformando, gradualmente, em um objeto de concorrência, associadas ao próprio mercado e, portanto, regidas pela "economia baseada no (cercamento do) conhecimento" (AZEVEDO, 2014, p. 110).

Como qualquer outro recorte do espaço social, o campo econômico é "um campo de lutas para conservar ou transformar esse campo de forças" (BOURDIEU, 2004, p. 22). Ao transpor seus princípios para o ambiente das universidades, estimula a cultura da competitividade entre essas instituições. Isso explica porque, na atualidade, a educação superior mundial lida com uma dimensão econômica sem precedentes em qualquer outro momento de sua evolução, validando a lógica de mercado associada a ela e explicitando uma oposição à sua concepção com bem público. Esse fato contribui fortemente para que, muitas vezes, as universidades sejam estimuladas a gerar patentes em determinados setores, superando, em muitos casos, as próprias empresas (ALTBACH; SALMI, 2011).

Os desafios da educação superior na economia do conhecimento implicam reconhecer que "os efeitos da globalização não atingem apenas os modos de produção, mas, também, a socialização ou a distribuição e o uso dos conhecimentos" (DIAS SOBRINHO, 2005, 169). Em uma sociedade cujas transformações têm contribuído para a instalação desse tipo de economia tem aumentado, cada vez mais, a centralidade do papel da educação superior para as estratégias de inovação e desenvolvimento dos países. Esse fato atesta o surgimento de uma nova epistemologia para a educação superior no século XXI que, em sua essência, "sustenta as razões pelas quais as universidades devem trilhar caminhos globais e internacionais, redesenhar seu perfil em 
SOUSA, J. V. de

direção aos mercados e desenvolver modalidades de capitalismo acadêmico" (LEITE; GENRO, 2012, p. 764).

Com efeito, a economia do conhecimento encontra-se fortemente impregnada no contexto da universidade. Disso advém, dentre outras, uma grande limitação para a função social dessa instituição: a concepção, por analogia, do seu trabalho na lógica industrial, empobrecendo-o, à medida que tende a limitá-lo ao campo empresarial. Para tanto, é promovida uma hipervalorização do discurso da eficiência, da eficácia, da excelência, da meritocracia, bem como dos parâmetros e indicadores de um padrão de qualidade transposto do mercado para a educação superior.

\begin{abstract}
A eficácia dos meios está na ordem-do-dia e parece tornar-se uma meta comum. A racionalização dos padrões de gestão na área de educação, por exemplo, indica, pelo menos, duas finalidades, uma externa e outra interna. A primeira, externa, diz respeito à necessidade de aperfeiçoar os recursos destinados à instituição, mediante transferência global dos recursos, avaliação do desempenho dos cursos/programas e da maior competição. A segunda, interna, refere-se à necessidade de permitir um melhor gerenciamento da área [...] levando as instituições a destacarem-se nesse campo da atividade acadêmica, bem como constituir uma identidade mais organizacional e funcional (OLIVEIRA, 2015, p. 356).
\end{abstract}

Em suma, na economia do conhecimento, determinadas tensões são intensificadas, induzindo as universidades interessadas a aderir aos critérios internacionais de qualidade, visando à conquista do título de world-class universities. Todavia, como alerta Bourdieu (2002), "o estabelecimento de um genuíno internacionalismo científico [...] é o começo do internacionalismo" [porque] a vida intelectual não é espontaneamente internacional (p. 3).

\title{
WORLD-CLASS UNIVERSITIESE RANKINGS INTERNACIONAIS NA EDUCAÇÃO SUPERIOR
}

Na perspectiva de Altback e Salmi (2011), em diferentes regiões do mundo, a construção do conceito de world-class universitie como um novo modelo de universidade representa um grande desafio para a educação superior. Uma das principais razões para isso é que essas universidade lutam por se instalar em um campo competitivo que conta com determinados mecanismos que visam submetê-las a condicionantes, pois constituem referências básicas para que possam se distinguir das demais. Diante disso, a noção de campo (BOURDIEU, 1983) ajuda no reconhecimento de que o conceito em questão é construído em meio às lutas travadas no campo da educação superior, visto que nele a posição distintiva das world-class universities nos rankings internacionais é assegurada a partir da aceitação e atendimento a critérios e padrões globais de qualidade. Assim, a forma como lidam com esses dois elementos revela que elas estabelecem uma relação de aliança/conflito, de concorrência e/ou de cooperação com eles.

Todavia, ainda que ambicionada por muitos países, a instalação de uma worldclass universitie não se dá de forma tranquila, mas em meio a polêmicas e dilemas. Tais elementos fazem-se presentes no processo considerando que a própria concepção desse modelo de universidade é objeto de intensas disputas por diferentes atores, validando a 
constatação de Altbach (2004) de que "todos querem uma (universidade classe do mundo ou mundial), ninguém sabe o que é, e tampouco alguém sabe como adquirir uma" (p. 2).

Dentre outras, uma das razões pelas quais o conceito de world-class universitieé disputado por diferentes grupos é que sua construção envolve interesses diversos políticos, econômicos, acadêmicos etc. -, expressos pelos distintos grupos que atuam na educação superior. A defesa desses interesses contribui, significativamente, para produzir competição global por talentos para atuar nesse tipo de universidade. "Premiações e prestígio institucional para membros do corpo docente são outorgados principalmente com base em produtividade de pesquisa" (ALTBACH, 2004, p. 21). Em decorrência do seu capital acadêmico e da lógica que rege o campo científico do qual participam, esses professores-pesquisadores acabam se transformando em atores fundamentais em diferentes órgãos de fomento à pesquisa com projeção internacional, nacional e regional. Concretamente, revelam possuir junto a esses órgãos determinado nível de decisão para realimentar a definição de excelência associada às world-class universities.

Concretamente, essas universidades compõem um grupo restrito e seleto de instituições, sendo dotadas de grande singularidade conquistada a partir dos resultados, patenteados tanto no ambiente acadêmico como junto ao próprio mercado, fatores que contribuem, significativamente, para seu reconhecimento como peças-chaves para o desenvolvimento dos países ou regiões onde se situam. Diante disso, suas principais características são: (i) excelência na pesquisa conquistada a partir do desenvolvimento de projetos de investigação que obedecem aos padrões de qualidade internacional; (ii) liberdade de pesquisa, ensino e expressão, traduzida em um amplo leque de possibilidades para que professores, pesquisadores e estudantes possam optar por quais linhas ou projetos de pesquisa desejam se vincular, considerando a diversidade de formas de socialização dos resultados de seus estudos; (iii) autonomia acadêmica extensiva aos diferentes indivíduos na definição de prioridades, construção e participação em diferentes arquiteturas acadêmicas; (iv) infraestrutura adequada que garanta diversificados espaços de ensino e aprendizagem com parques tecnológicos, acervos bibliográficos e laboratórios de pesquisa, dentre outros, em quantidade e qualidade satisfatórias ao desenvolvimento das atividades universitárias; (v) financiamento garantido por recursos financeiros que podem resultar de investimentos públicos ou de parcerias público-privado, tendência fortemente revelada nos países do hemisfério norte; (vii) cosmopolitismo traduzido na visão multicultural que resulta da interação de diferentes grupos de indivíduos; (vii) diversidade derivada das práticas institucionais dos atores e de sua convivência com indivíduos com distintas origens culturais e sociais (ALTBACH, 2004).

Tendo características como essas e visando a assegurar um padrão de excelência, as world-class universities demandam expressivos recursos capazes de garantir processos históricos de aprendizagem demorados e complexos. Todavia, as práticas que resultam desses processos não são facilmente replicáveis por outras universidades que também buscam alcançar o mesmo patamar e reconhecimento do seu prestígio frente às demais. Apresentado atributos singulares e diferenciados que se mostram decisivos para seu reconhecimento diante das demais, essas universidades contam com 
SOUSA, J. V. de

\begin{abstract}
[...] professores altamente qualificados, resultados de excelência em pesquisa, qualidade no ensino e na aprendizagem, altos níveis de financiamento governamental e não governamental, estudantes internacionais e talentosos, liberdade acadêmica, estrutura de governança autônoma e instalações bem equipadas para ensino, pesquisa, administração e - muitas vezes - para alojamento estudantil (ALTBACH; SALMI, 2011, p. 3).
\end{abstract}

Ao investir em uma performance cuja finalidade é assegurar sua distinção no competitivo campo da educação superior, as world-class universities trabalham com indicadores de desempenho que correspondem a parâmetros internacionais de qualidade, o que ajuda em sua definição como instituições mundiais. De acordo com Altbach (2004), embora sendo diversos, todos esses indicadores são alinhados a padrões globais que focalizam a dinâmica desse tipo de universidade, destacando-se: número de trabalhos que produzem, diplomas acadêmicos, publicações, transferência de tecnologia, captação de fundos, projetos nacionais e internacionais aprovados, quantidade de prêmios científicos que recebem, número de patentes que adquirem e contingente de professores e estudantes estrangeiros. Ao estruturar suas práticas a partir desses critérios, acabam estabelecendo relações de cumplicidade e conflito (BOURDIEU, 1983) tanto com os atores e instituições que os definem como com os próprios critérios que passam a atender.

Todavia, como estão inseridas em um campo marcado por contradições e impasses, muitas vezes, ao optarem por atender os referidos critérios, as world-class universities entram em choque com outra necessidade sua - a construção de uma identidade institucional, levando em conta seu compromisso em servir aos interesses nacionais. Nesse sentido, Altbach (2004) alerta para a existência de argumentos positivos relativos aos esforços das universidades para se tornarem de classe mundial, mas também a riscos potenciais para que elas alcancem essa posição de reconhecimento e prestígio no campo da educação superior. Os argumentos positivos estão associados a elementos como aumento dos resultados de pesquisa e publicações, avanços significativos na aprendizagem dos estudantes, modernização no parque tecnológico e na gestão dos campus, dentre outros. Os riscos potenciais mais evidentes dizem respeito à concentração dos esforços institucionais sem considerar, de maneira cuidadosa, o próprio contexto da universidade, visto que a referência básica passa a ser alta produção internacionalizada.

Ainda segundo Altbach (2004), na discussão sobre as world-class universities é importante considerar que a globalização da erudição, as normas de disciplina, os métodos eleitos como os mais produtivos para a pesquisa e os temas tendem a ser estabelecidos pelos pesquisadores líderes de países ocidentais. Essa perspectiva é compartilhada por Song (2018) ao enfatizar que o poder acadêmico do discurso é controlado pelos sistemas universitários desses países "e o mercado estudantil é dominado e dividido pelas potências tradicionais" (p. 739).

No contexto de hegemonia no qual as world-class universities se inserem e buscam garantir posição de distinção, o inglês tem se configurado como a língua franca. Considerando a competitividade que caracteriza o campo da educação superior, é razoável supor que isso traz um favorecimento aos países que têm o inglês como língua materna e, consequentemente, aos seus estudantes. $O$ caráter hegemônico da língua 
inglesa é defendido, inclusive, pela Organização para a Cooperação e Desenvolvimento Econômico (OCDE), outro ator que revela grande interesse no campo em questão.

A linguagem da instrução é um forte determinante da escolha de destino dos estudantes. O inglês é a língua franca do mundo globalizado, com uma em cada quatro pessoas usando globalmente. Não surpreendentemente, os países onde o inglês é uma língua oficial [...] são os principais países de destino da OCDE para estudantes internacionais (OECD, 2017, p. 294 - tradução nossa).

Também a concentração geográfica das world-class universities revela o caráter hegemônico delas, considerando os dados revelados pelas duas mais expressivas e pioneiras classificações comparativas internacionais - Academic Ranking of World Universities (ARWU) e Times Higher Education World University Rankings (THE). A maioria absoluta das vinte universidades mundiais melhor classificadas por esses dois rankings, respectivamente, em 2019 e 2020, concentra-se nos Estados Unidos, estando todas elas em países ocidentais ou anglo-saxões, situados no hemisfério norte.

O primeiro ranking mencionado aponta que, em 2019, dezesseis das vinte universidades consideradas como as melhores do mundo, correspondendo a $80,0 \%$ delas, são norte-americanas, enquanto três pertencem ao Reino Unido e uma é Suíça, como mostram os dados do quadro a seguir.

Quadro 1 - As 20 melhores universidades do mundo - Academic Ranking of World Universities/ARWU(2019)

\begin{tabular}{|r|l|l|}
\hline Posição & \multicolumn{1}{|c|}{ Instituição } & País \\
\hline $\mathbf{1}$ & Harvard University & EUA \\
$\mathbf{2}$ & Stanford University & EUA \\
$\mathbf{3}$ & University of Cambridge & UK \\
$\mathbf{4}$ & Massachusetts Institute of Technology - MIT & EUA \\
$\mathbf{5}$ & University of California, Berkeley & EUA \\
$\mathbf{6}$ & Princeton University & EUA \\
$\mathbf{7}$ & University of Oxford & UK \\
$\mathbf{8}$ & Columbia University & EUA \\
$\mathbf{9}$ & California Institute of Technology & EUA \\
$\mathbf{1 0}$ & University of Chicago & EUA \\
$\mathbf{= 1 1}$ & University of Califórnia, Los Angeles & EUA \\
\hline
\end{tabular}




\begin{tabular}{clc}
$\mathbf{1 1}$ & Yale University & EUA \\
$\mathbf{1 3}$ & Cornell University & EUA \\
$\mathbf{1 4}$ & University of Washington & EUA \\
$\mathbf{1 5}$ & University College London & UK \\
$\mathbf{1 6}$ & Johns Hopkins University & EUA \\
$\mathbf{1 7}$ & University of Pennsylvania & EUA \\
$\mathbf{1 8}$ & University of California, San Diego & EUA \\
$\mathbf{1 9}$ & Swiss Federal Institute of Technology Zurich & Switzerland \\
$\mathbf{2 0}$ & Washington of California San Francisco & EUA \\
\hline
\end{tabular}

Fonte: Disponível em: http://www.shanghairanking.com/arwu2019.html Acesso em: 30 jan. 2020.

Como evidenciam esses dados, a metodologia adotada pelo ranking ARWUlevou à classificação de duas universidades mundiais na mesma posição (11a), em 2019 University of Califórnia/Los Angeles e Yale University -, ambas localizadas nos Estados Unidos. Ainda que tenha uma metodologia própria, o outro ranking (THE) adotou procedimento semelhante, em 2020, ao classificar na $13^{\text {a }}$ posição a University of California/Berkeley e o Swiss Federal Institute of Technology Zurich, sendo a primeira situada também nos Estados Unidos e a segunda na Suíça, como mostra o próximo quadro.

Quadro 2 - As 20 melhores universidades do mundo - Times Higher Education - THE (2020)

\begin{tabular}{|r|l|c|}
\hline Posição & \multicolumn{1}{|c|}{ Instituição } & País \\
\hline $\mathbf{1}$ & University of Oxford & UK \\
$\mathbf{2}$ & California Institute of Technology & EUA \\
$\mathbf{3}$ & University of Cambridge & UK \\
$\mathbf{4}$ & Stanford University & EUA \\
$\mathbf{5}$ & Massachusetts Institute of Technology - MIT & EUA \\
$\mathbf{6}$ & Princeton University & EUA \\
$\mathbf{7}$ & Harvard University & EUA \\
$\mathbf{8}$ & Yale University & EUA \\
$\mathbf{9}$ & University of Chicago & EUA \\
$\mathbf{1 0}$ & Imperial College of London & UK \\
$\mathbf{1 1}$ & University of Pennsylvania & EUA \\
$\mathbf{1 2}$ & Johns Hopkins University & EUA \\
$\mathbf{= 1 3}$ & University of California, Berkeley & EUA \\
\hline
\end{tabular}




\begin{tabular}{|clc}
\hline $\mathbf{1 3}$ & Swiss Federal Institute of Technology Zurich & Switzerland \\
\hline $\mathbf{1 5}$ & University College of London & UK \\
$\mathbf{1 6}$ & Columbia University & EUA \\
$\mathbf{1 7}$ & University of Califórnia, Los Angeles & EUA \\
$\mathbf{1 8}$ & University of Toronto & Canada \\
$\mathbf{1 9}$ & Cornell University & EUA \\
$\mathbf{2 0}$ & Duke University & EUA \\
\hline Fonte: & Disponível em: https://www.timeshighereducation.com/world-university- \\
rankings/2020/world-ranking\#!/page/0/length/25/sort by/rank/sort order/asc/cols/stats
\end{tabular}

Os dados desse segundo quadro comprovam que a classificação feita pelo ranking THE reitera a ausência de universidades do hemisfério sul entre as 20 melhor classificadas no mundo, em 2020. Além disso, apontam que, praticamente, dois terços delas - equivalente a 14 instituições - situam-se nos Estados Unidos, enquanto as demais distribuem-se da seguinte forma: quatro no Reino Unido, uma no Canadá e outra na Suíça.

A concentração das world-class universities no mundo ocidental e no hemisfério norte revela uma hegemonia de poucos países na instalação e consolidação delas no competitivo campo da educação superior. Tal situação tem preocupado os governos de outros países que também reconhecem a expansão e o fortalecimento dos seus sistemas universitários como elementos fundamentais aos seus projetos políticos. Nesse cenário, um exemplo é a China, que decidiu selecionar grupos de universidades e apoiá-las com substantivos recursos, visando que se tornem de classe mundial em um futuro próximo. Dando materialidade a essa decisão, em outubro de 2015, o Conselho de Estado chinês instituiu o "Plano geral para impulsionar a iniciativa de universidade de primeira classe mundial e construção de disciplinas de primeira classe" (SONG, 2018, p. 731).

Decisões estatais como essa decorrem do fato de que não apenas as universidades chinesas, mas a maioria das asiáticas enfrenta uma situação de desvantagem, à medida que passaram a exportar grandes talentos para outras que já são reconhecidas como world-class universities. Isso fez com que, nas últimas décadas, um expressivo contingente de estudantes de países emergentes, notadamente asiáticos, acabasse se deslocando para estudar em universidades de países de língua inglesa. $\mathrm{Na}$ visão de Marginson (2008), esse fenômeno provoca, ao mesmo tempo, um fluxo unidirecional de estudantes e transformações culturais assimétricas, que têm origem e explicação na competição global que caracteriza o campo da educação superior, como discutido neste texto.

\section{CONSIDERAÇÕES FINAIS}

O esforço interpretativo revelado ao longo deste artigo buscou situar a educação superior no contexto mais amplo da sociedade globalizada e da educação superior na 
SOUSA, J.V. de

economia do conhecimento, visando sua compreensão como fenômenos inseridos em uma totalidade concreta. A busca dessas referências teve como propósito fundamentar a problematização do conceito de world-class universitie como objeto de disputa por diferentes grupos interessados na dinâmica do competitivo campo da educação superior.

A reflexão empreendida considerou que a concepção desse novo modelo de universidade implica pensar, ao mesmo tempo, sobre a cultura que a universidade, como instituição histórica, dissemina na sociedade contemporânea seu ideário político. Para tanto, é preciso considerar que isso ocorre em um mundo globalizado, cujas transformações acabam afetando, também, os cenários regional e local da educação superior.

As mudanças na educação superior mundial têm ocorrido em diversos aspectos, estimulando, de forma crescente, a instalação de uma nova tipologia de universidade com características institucionais e práticas acadêmicas bastante diversificadas. Como modelo representativo dessa tendência, a world-class universitie atua tomando como referência padrões de qualidade assumidos globalmente.

O conceito de world-class universitie é construído tendo como referência padrões e critérios globais de qualidade, mas também levando em conta as demais universidades que fazem parte do campo da educação superior. Concretamente, o seu grau de reconhecimento diante das demais acontece em níveis variados em função, dentre outros motivos, da trajetória que possui, do nível de adesão aos critérios globais de qualidade e das influências que suas práticas sofrem da economia do conhecimento.

Nos contextos emergentes, a educação superior constitui elemento indispensável para o desenvolvimento do projeto político dos países, porém incorporando princípios econômicos e sendo objeto de interesse de vários grupos. $\mathrm{Na}$ composição desses grupos, destacam-se governos nacionais, policy makers, reitores, pesquisadores, docentes, estudantes, representante de categorias profissionais e do setor privado, que estabelecem relações em uma universidade com vocação e missão bastante diferenciada, pautadas na competitividade e na economia do conhecimento.

A construção das world-class universities se dá tomando como referência padrões de qualidade assumidos globalmente. Na luta da qual participam no campo da educação superior, essas universidades investem em sua autonomia na gestão e na liberdade para promoverem mudanças em seu percurso, visando manter-se em posição favorável no ranking do qual participam e a partir do qual desejam manter visibilidade mundial.

Artigo recebido em: 01/02/2020

Aprovado para publicação em: 17/05/2020

\section{WORLD-CLASS UNIVERSITIES AS A CONCEPT IN DISPUTE IN HIGHER EDUCATION}

ABSTRACT:This article aims to analyze the concept of world-class universities as an object of dispute in the competitive field of higher education, based on the premise that in the globalized world its origin and consolidation occur taking as a basic reference international quality standards. Of a theoretical nature, the work problematizes higher education in the knowledge economy, in an articulated way to the exploration of data produced by the two main rankings that classify these universities - Academic Ranking of World Universities and Times Higher Education World University 
Rankings - published, respectively, in years 2019 and 2020. It is concluded that the concept of this new university model considers global quality criteria and indicators, but also the action of the other universities that are part of the field of higher education.

KEYWORDS: Higher Education. Knowledge economy. World-class universities.

UNIVERSIDADES DE CLASE MUNDIAL COMO CONCEPTO DE DISPUTAS EN LA EDUCACIÓN SUPERIOR

RESUMEN: El artículo tiene como objetivo analizar el concepto de universidades de clase mundial como objeto de disputa en el campo competitivo de la educación superior, en base a la premisa de que en el mundo globalizado su origen y consolidación ocurren tomando como referencia los estándares internacionales de calidad básicos. De naturaleza teórica, el trabajo problematiza la educación superior en la economía del conocimiento, de manera articulada a la exploración de los datos producidos por las dos clasificaciones principales que clasifican estas universidades: Clasificación académica de universidades mundiales y Clasificación mundial de universidades de Times Higher Education, publicadas, respectivamente, en años 2019 y 2020. Se concluye que el concepto de este nuevo modelo universitario considera criterios e indicadores de calidad global, pero también la acción de las otras universidades que forman parte del campo de la educación superior.

PALABRAS CLAVE: Educación universitária. Economia del conocimiento. Universidad de classe mundial.

\section{REFERÊNCIAS}

ALTBACH, P. G. The costs and benefits of world-class universities. Academe, EUA, 2004, p. 20-23.

ALTBACH, P. G. International Higher Education: reflections on policy and pratice. Massachusetts, Center for International Higher Education Lycnh School of Education, Boston College, 2006.

ALTBACH, P. G. SALMI, J. Introdução. In: ALTBACH, P. G. SALMI, J. (Eds.). The road to academic excellence: the making of world-class research universities. Washington, The World Bank, 2011, p. 4-18.

AZEVEDO, M. L. N. A economia baseada no "cercamento" do conhecimento: globalização, seigniorage e mercadorias fictícias. 35ª Reunião Nacional de Pós-Graduação e Pesquisa em Educação (ANPEd). Anais... Porto de Galinhas/PE: UFPE, 2012, p. 1-17. Disponível em: http://www.35reuniao.anped.org.br/trabalhos/113-trabalhos-gt11-politica-deeducacao-superior. Acesso em: 28 jan. 2020. 
SOUSA, J. V. de

AZEVEDO, M. L. N. A internacionalização da Educação Superior em questão: mitos, enganos e verdades. Horizontes Latinoamericanos: Revista de Humanidades e Ciências Sociais do Mercosul Educacional, Mercosul, v. 3, n. 1, 2014, p. 99-110

BOURDIEU, P. Coisas ditas. São Paulo: Brasiliense, 1990.

BOURDIEU, P. Os usos sociais da ciência: por uma sociologia clínica do campo científico. São Paulo: UNESP, 2004.

BOURDIEU, P. 0 poder simbólico, 14. ed. Rio de Janeiro, Bertrand Brasil; Lisboa: Difel, 2010.

CHARLE, C.; VERGER, J. História das universidades. São Paulo: Editora da Universidade Estadual Paulista, 1996.

CLARK, B. R. Sustaining change in universities: continuities in case studies and concepts. Plenary Address. 24th Annual EAIR Forum, EUA, September 8-11, 2002, Prague, Czec Republic.

DE WIT, H. An introduction to higher education internationalisation. Milan, Vita e Pensiero, 2013.

DIAS SOBRINHO, J. Educação superior, globalização e democratização. Qual universidade? Revista Brasileira de Educação, Rio de Janeiro, n. 28, jan./abr. 2005, p. 164-173.

DIAS SOBRINHO, J. Dilemas da educação superior no mundo globalizado: sociedade do conhecimento ou economia do conhecimento? São Paulo: Casa do Psicólogo, 2010.

ENDERS, J. Higher education in a globalising world. Boston: Kluwer Academic Publishers, 2002.

FRANCO, M. E. D. P. ; MOROSINI, M. C. Arquiteturas acadêmicas na educação superior. In: SEGENREICH, S. C. D. (Org.). Organização institucional e acadêmica na expansão da educação superior - glossário. Rio de Janeiro: Publit, 2017, p. 21-25.

GARCÍA GUADILLA, C. Tensiones y transiciones: educación superior latinoamericana en los albores del tercer milenio. Caracas: Editorial Neuva Sociedad, 2004.

HUDZIK, J K. Changing paradigm and practice for higher education internationalization. In: DE WIT, H. (Org.). An introduction to higher education internationalization. Centre for Higher Education Internationalisation (CHEI), Università Cattolica del Sacro Cuore, Milan/Italy, 2013, p. -38-59.

KERR, C. Os usos da universidade: universidade em questão. Brasília: Editora UnB, 2005. 
KNIGHT, J. Five truths about internationalisation. International Higher Education. Boston College. Center for International Higher Education. International Issues, n. 69, 2012, p. 4-5.

LEITE, D. ; GENRO, M. E. H. Avaliação e internacionalização da educação superior: quo vadis America Latina? Avaliação, Sorocaba, v. 17, n. 3, p. 763-785, nov. 2012.

LEMERT, C.; ELLIOT, A. Globalization: a reader. New York: Routledge, 2010.

MARGINSON, S. Global field and global imagining: Bourdieu and worldwide higher education. British Journal of Sociology of Education, EUA, 2008, p. 303-315.

MOHRMAN, K.; MA, W.; BAKER, D. The research university in transition: the emerging global model. Higher Education Policy, EUA, v.21, p. 5-27, 2008:

MOROSINI, M. C. Qualidade da educação superior e contextos emergentes. Avaliação, Sorocaba, SP, v. 19, n. 2, p. 385-405, jul. 2014.

OLIVEIRA, J. F. A pós-graduação e a pesquisa no Brasil: processos de regulação e de reconfiguração da formação e da produção do trabalho acadêmico. Práxis Educativa, Ponta Grossa, v. 10, n. 2, p. 343-363, jul./dez. 2015.

OLIVEIRA, J. F.; MORAES, K. N. Produção do conhecimento na universidade pública no Brasil: tensões, tendências e desafios. Educação em Revista, Belo Horizonte, v.32, n. 04, p. 73-95, out. dez, 2016.

ORGANISATION FOR ECONOMIC CO-OPERATION AND DEVELOPMENT (OECD 2017). Education at a Glance 2017, OECD Indicators, OECD Publishing, Paris. http://dx.doi.org/10.1787/eag-2017-en Disponível em http://download.inep.gov.br/acoes_internacionais/eag/documentos/2017/relatorio_ed ucation_at_a_glance_2017.pdf. Acesso em 23 jan. 2020.

ORGANIZAÇÃO DAS NAÇÕES UNIDAS PARA A EDUCAÇÃO, A CIÊNCIA E A CULTURA. (UNESCO). Relatório publicado pela UNESCO ajuda cidadãos a reivindicar direito à educação. Disponível em: https://nacoesunidas.org/relatorio-publicado-pela-unescoajuda-cidadaos-a-reivindicar-direito-a-educacao/. Acesso em: 27 jan. 2020.

SCOTT, C. The Mision of the University. Medieval to Posmodern Transformations. Journal of Higher Education, EUA, vol. 77, n. 1, p. 2-39, 2006.

SONG, J. Creating world-class universities in China: strategies and impacts at a renowned research university. Higher Education, EUA, 2018, n. 75, 729-742. 
SOUSA, J. V. de

SQUIRRA, S. Sociedade do Conhecimento. In MARQUES DE MELO, J. M; SATHLER, L. Direitos à Comunicação na Sociedade da Informação. São Bernardo do Campo, SP, UMESP, 2005, p. 253-274.

TROW, M. Twentieth-century higher education: elite to mass to universal. Baltimore: The Johns Hopkins Press, 2011.

José VieIRA de SOUSA: Possui graduação em Pedagogia pela Associação de Ensino Unificado do Distrito Federal - AEUDF (1985) e em Letras Português pela Universidade de Brasília - UnB (1994). Mestrado em Educação (1994) e Doutorado em Sociologia (2003) pela UnB. Pós-Doutorado em andamento pela Universidade Federal de Goiás (UFG) e Universidade do Minho (UM) - Braga/Portugal. Líder do Grupo de Estudos de Políticas de Avaliação de Educação Superior (GEPAES) no Diretório de Grupos de Pesquisa do Brasil/CNPq. Professor Associado IV da UnB.

Orcid: https://orcid.org/0000-0002-6948-1549

E-mail:sovieira@unb.br

Este periódico utiliza a licença Creative Commons Attribution 3.0, para periódicos de acesso aberto (Open Archives Iniciative - OAI). 